\title{
Vertically resolved concentration and liquid water content of atmospheric nanoparticles at the US DOE Southern Great Plains site
}

Haihan Chen et al.

Correspondence to: James N. Smith (jimsmith@uci.edu)

The copyright of individual parts of the supplement might differ from the CC BY 4.0 License. 
(a)

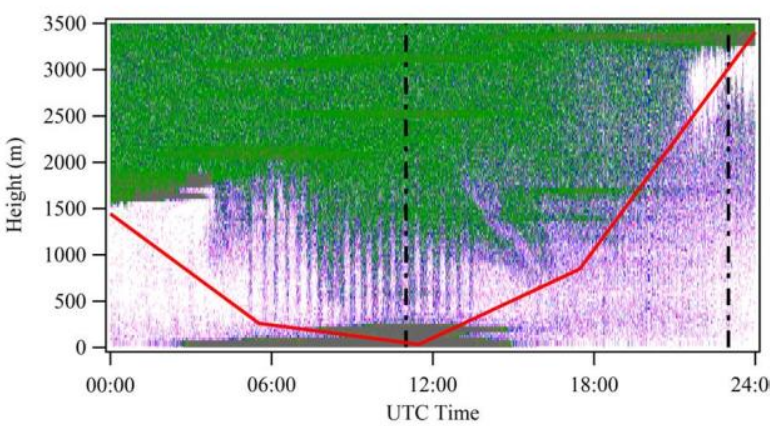

(b)

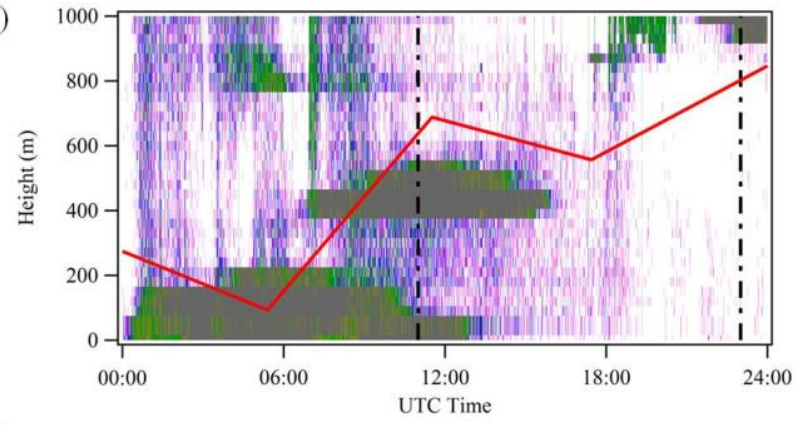

(c)

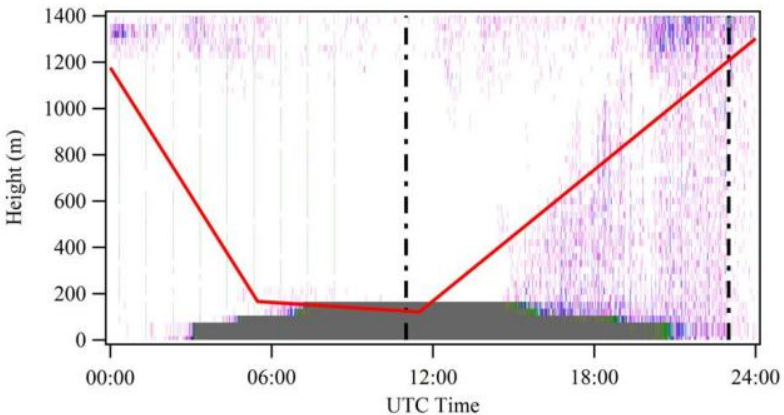

(d)

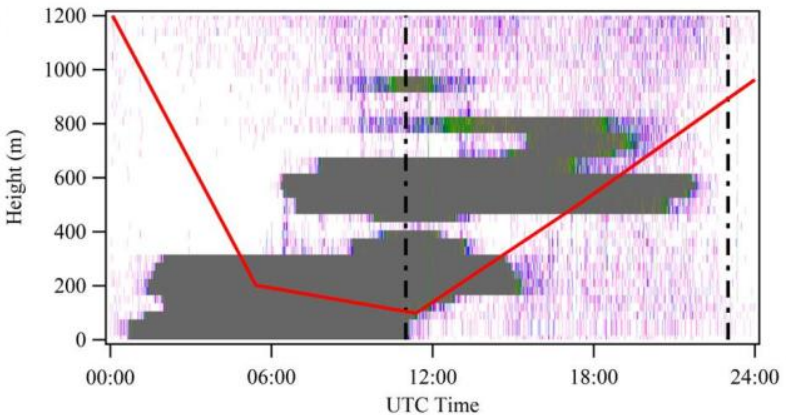

Figure S1. Vertically and temporally resolved atmospheric stability on (a) April 19, 2013, (b) May 9, 2013, (c) May 11, 2013, and (d) May 13, 2013 at SGP. The atmospheric stablity is classified into extremely unstable (grey), moderately unstable (magenta), slightly unstable (blue), neutral (green), slightly stable (brown) and moderately stable (white) regimes based on Richardson number. The two vertical dash lines represent 06:00 and 18:00 local time, respectively. The red line shows the boundary layer height determined from radiosonde data. 
(a)

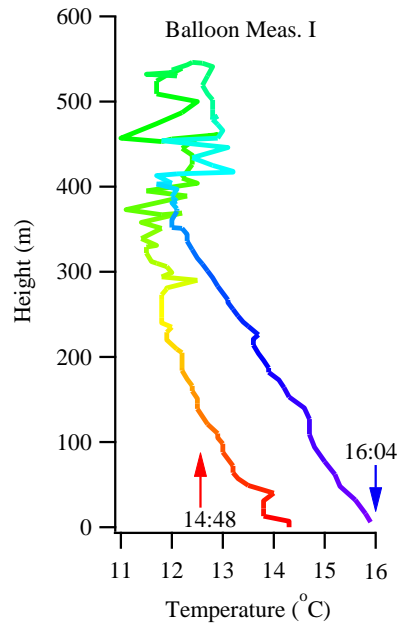

(c)

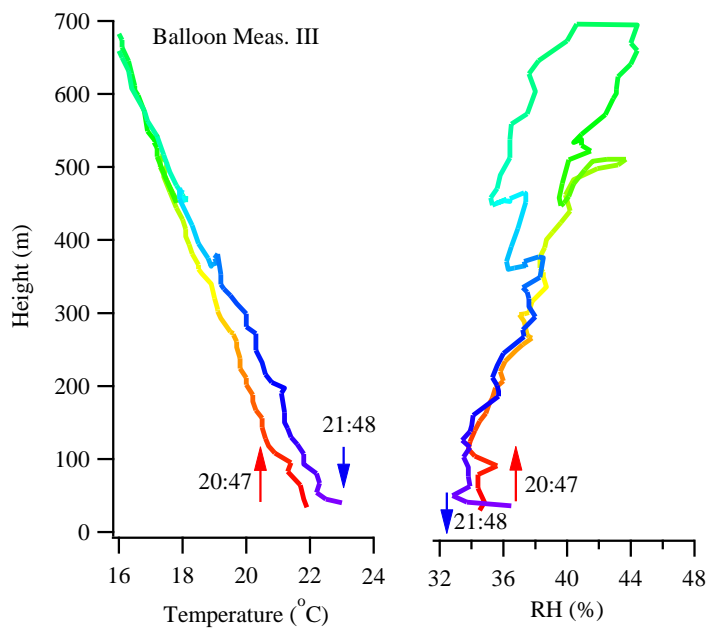

(b)
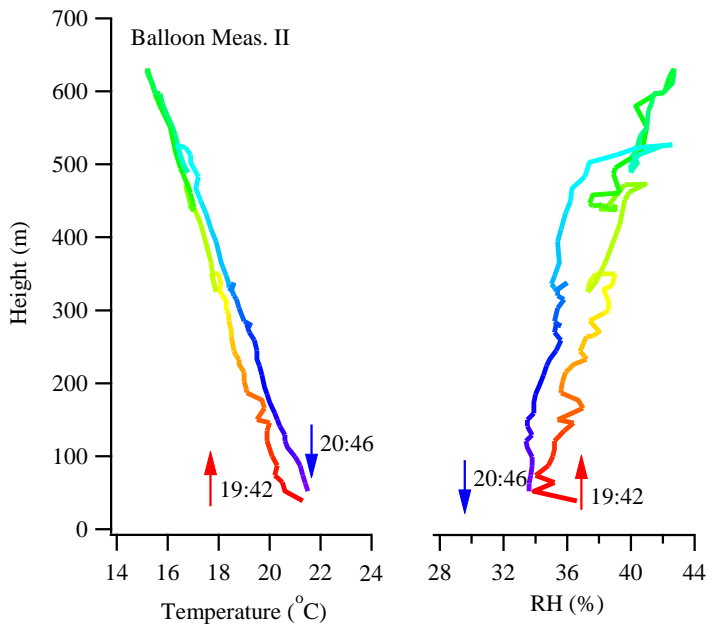

Figure S2. Vertical profiles of temperature and relative humidity measured by the tethered balloon system on May 12, 2013 at SGP. Three launches were made during the day. A rainbow color pattern is used to illustrate the time after the balloon measurements were started, with red representing the initial period and purple representing the final period of a launch. 
(a)

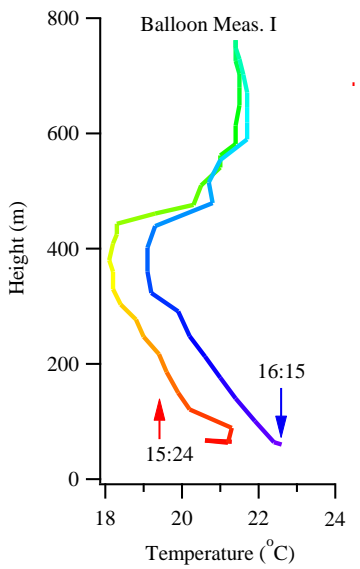

(c)

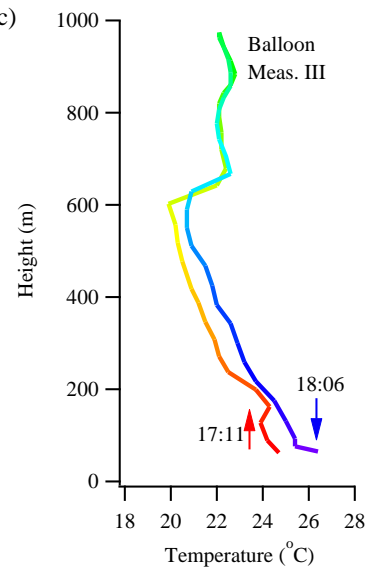

(e)

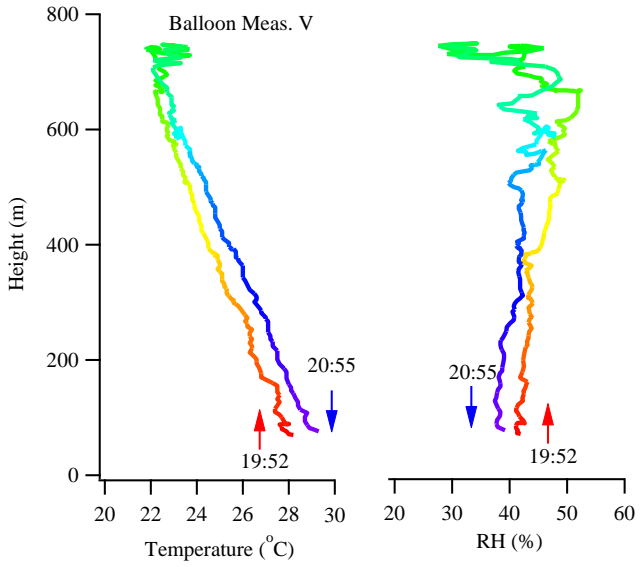

(b)
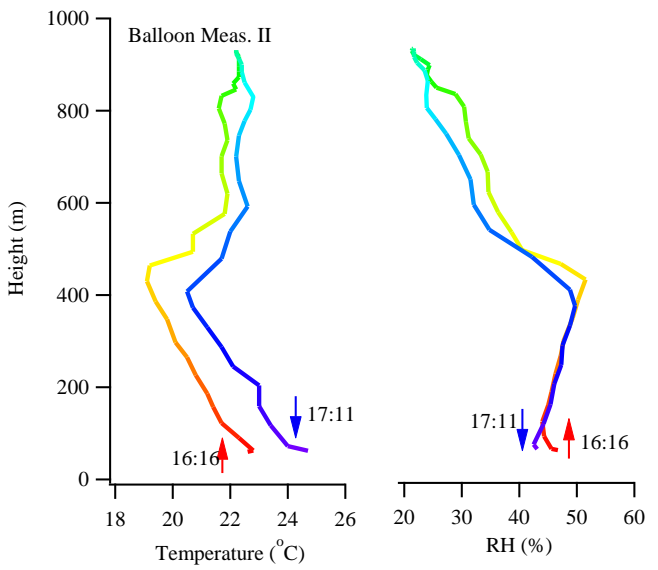

(d)

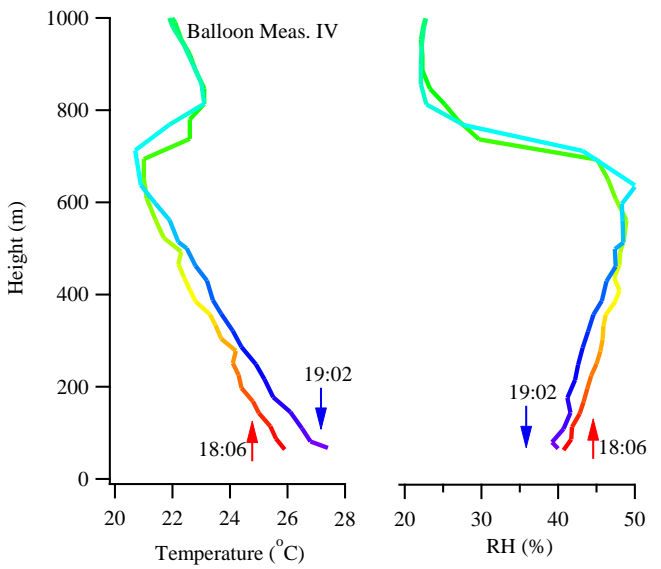

(f)

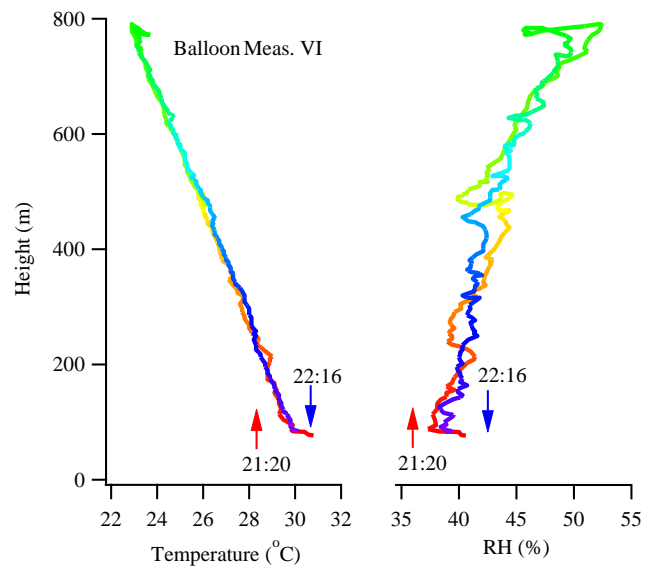

Figure S3. Vertical profiles of temperature and relative humidity measured by the tethered balloon system on May 13, 2013 at SGP. Six launches were made during the day. A rainbow color pattern is used to illustrate the time after the balloon measurements were started, with red representing the initial period and purple representing the final period of a launch. 
(a)

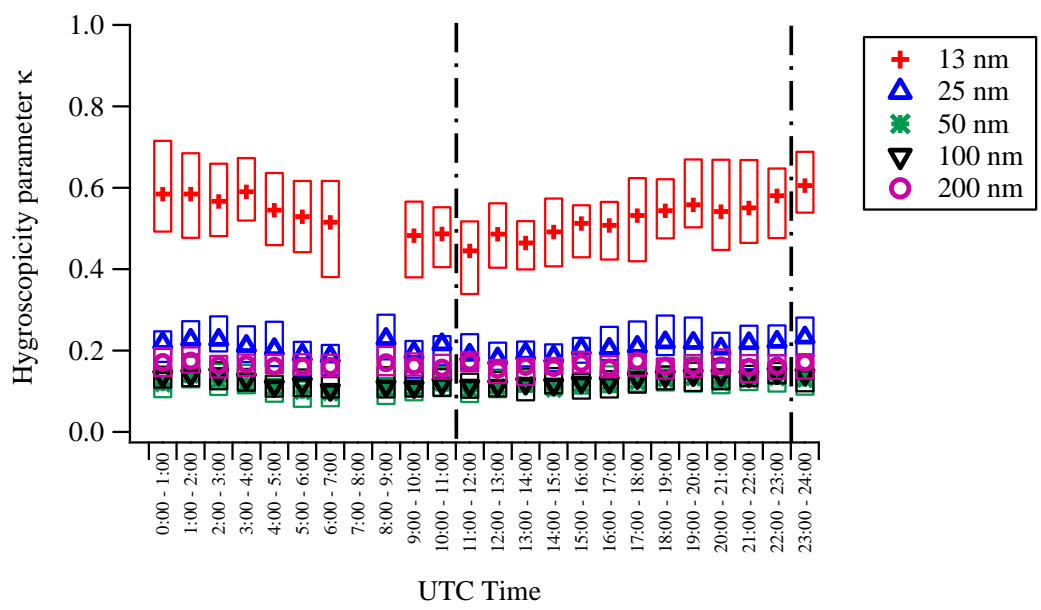

(b)

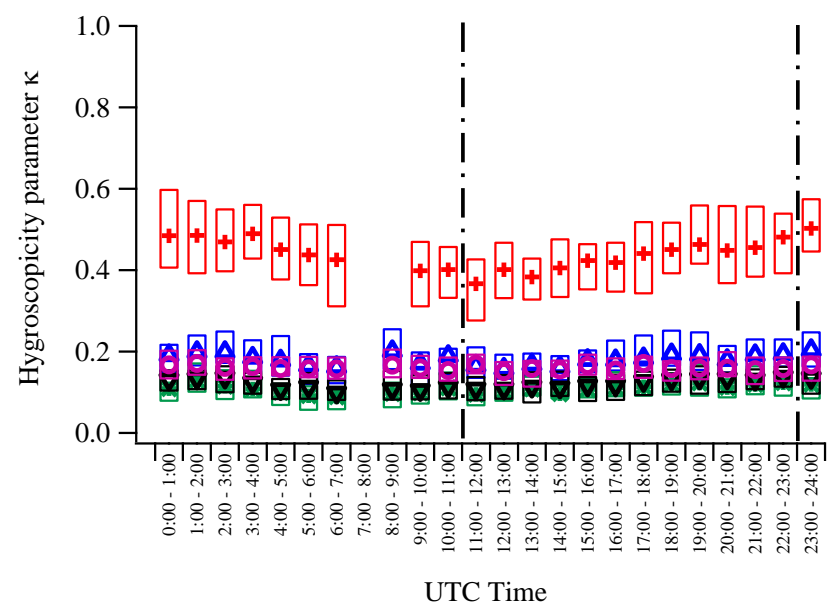

Figure S4. One-hour average hygroscopicity parameters $\kappa$ for 13, 25, 50, 100 and $200 \mathrm{~nm}$ particles determined by TDMA from April 13 - May 24, 2013 at SGP calculated assming a surface tension of the solution/air interface of (a) $0.0504 \mathrm{~J} \mathrm{~m}^{-2}$ and (b) $0.03 \mathrm{~J} \mathrm{~m}^{-2}$. The boxes represent $25-75 \%$ ranges of all measurements. The two vertical dash lines represent 06:00 and 18:00 local time, respectively. 
(a)

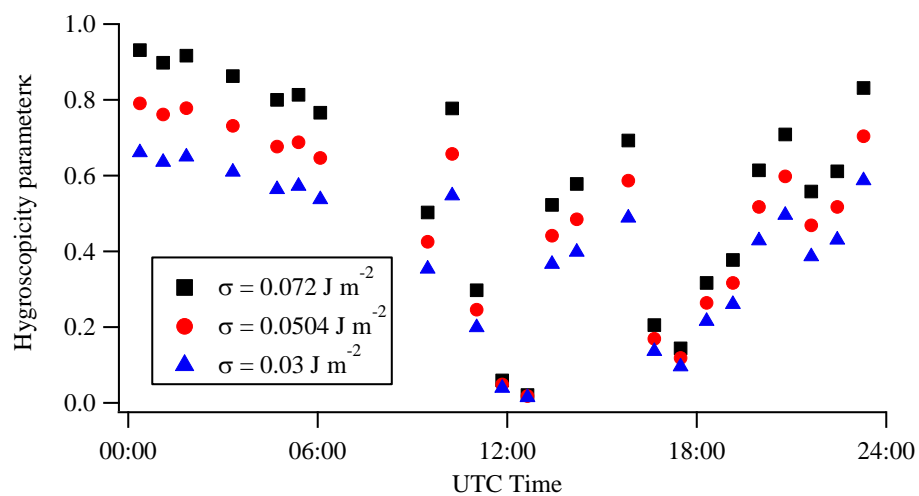

(b)

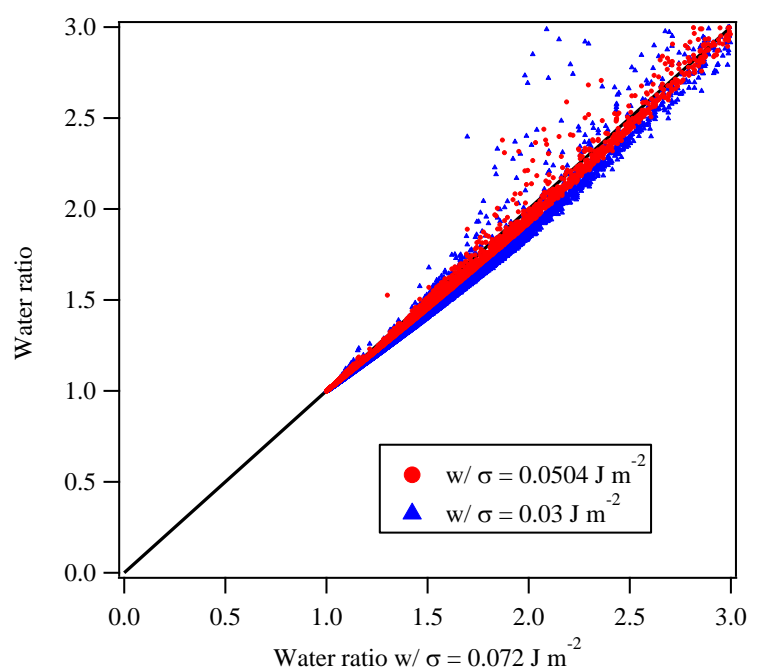

Figure S5. Comparison of (a) hygroscopicity parameter $\kappa$ and (b) estimated water volume ratio of 13-nm particles on May 12, 2013 with different values of surface tension, $0.072,0.504$ and $0.03 \mathrm{~J} \mathrm{~m}^{-2}$. 


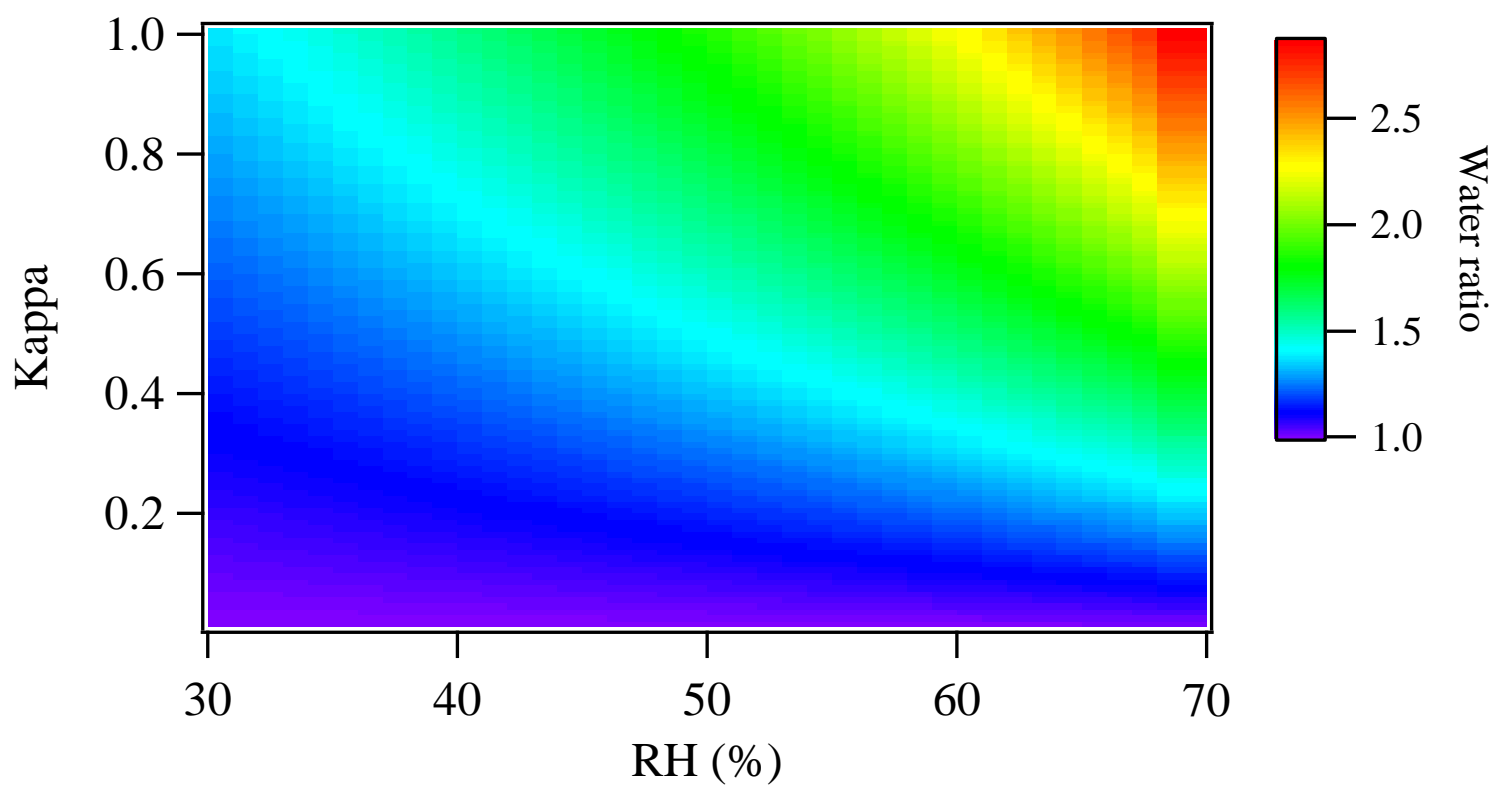

Figure S6. The dependence of water volume ratio of 13-nm particles as a function of Kappa value and R at $298.15 \mathrm{~K}$. 


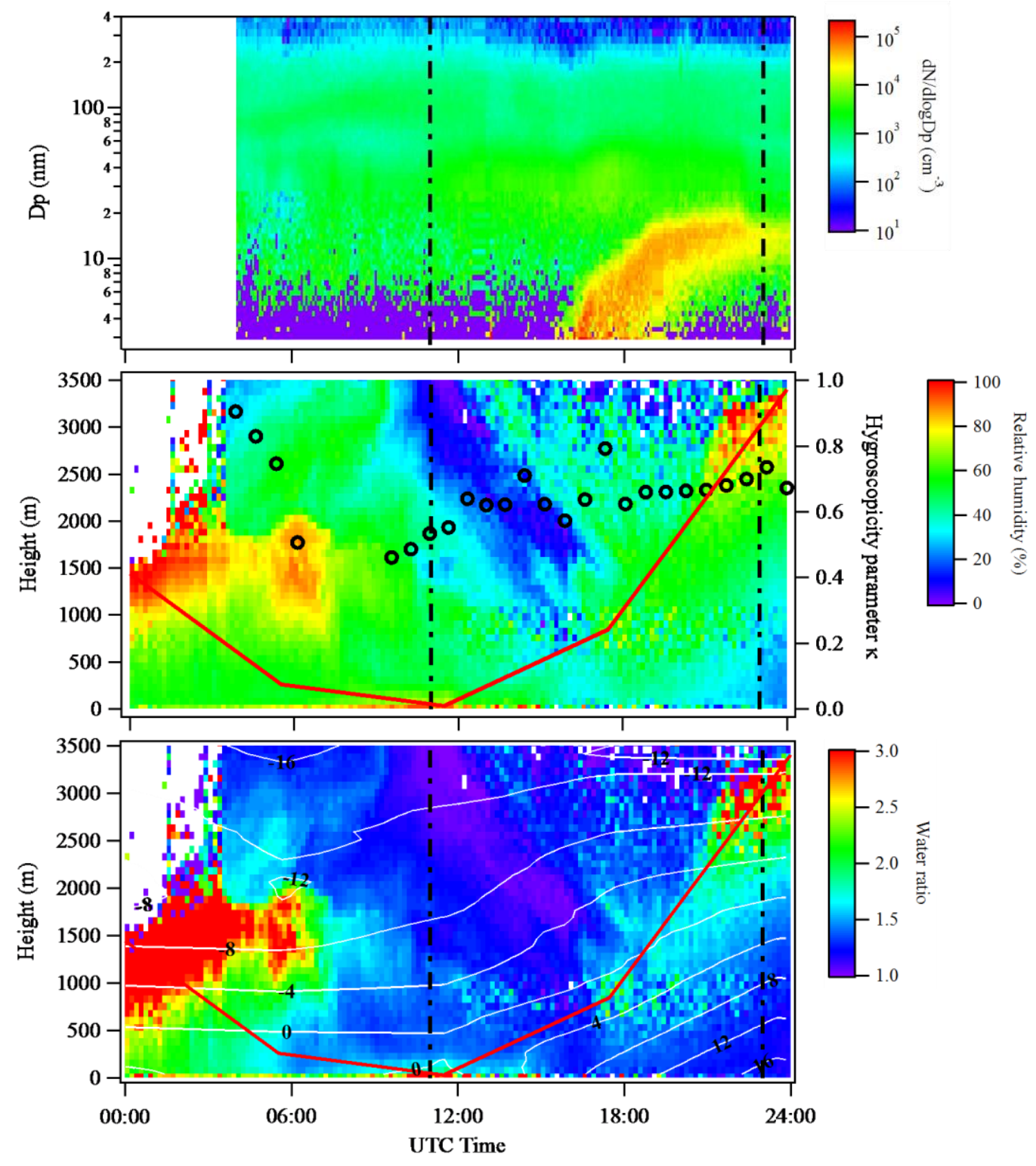

Figure S7. New particle formation event captured by scanning mobility particle sizers (upper plot), vertically and temperolly resolved relative humidity (middle plot) and estimated water volume ratio of a $13 \mathrm{~nm}$ particles (lower plot) on April 19, 2013 at SGP. The two vertical dash lines in each plot represent 06:00 and 18:00 local time, respectively. The red lines shows the boundary layer height determined from radiosonde data. Overlaid in the middle plot is the temperally resolved hygroscopicity paramter $\kappa$ of 13 $\mathrm{nm}$ particles obtained by TDMA (open black circles). Temperature $\left({ }^{\circ} \mathrm{C}\right)$ is shown with the white contour lines in the lower plot. 


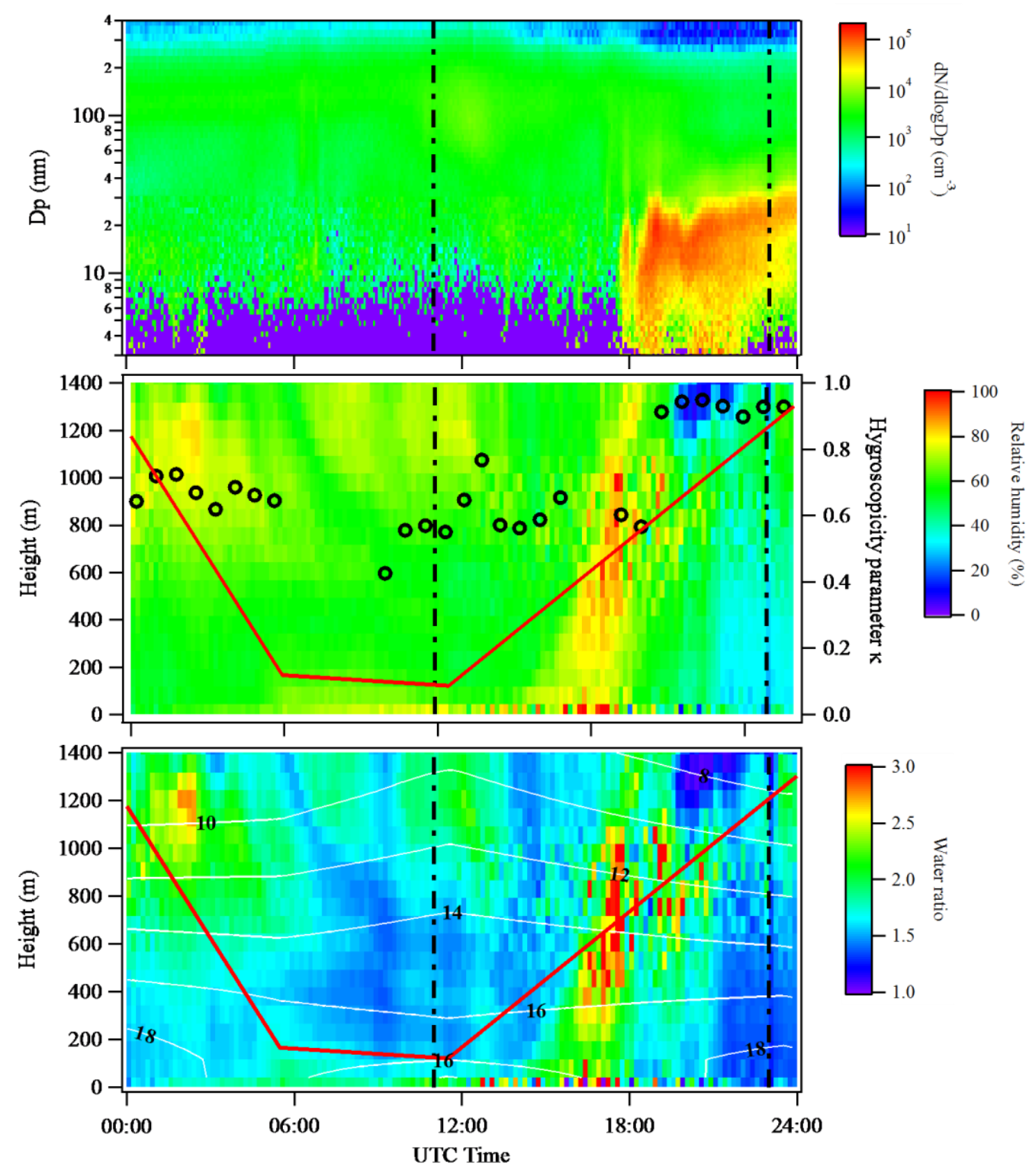

Figure S8. New particle formation event captured by scanning mobility particle sizers (upper plot), vertically and temperolly resolved relative humidity (middle plot) and estimated water volume ratio of a $13 \mathrm{~nm}$ particles (lower plot) on May 11, 2013 at SGP. The two vertical dash lines in each plot represent 06:00 and 18:00 local time, respectively. The red lines shows the boundary layer height determined from radiosonde data. Overlaid in the middle plot is temperolly resolved hygroscopicity paramter $\kappa$ of $13-\mathrm{nm}$ particles obtained by TDMA (open black circles). Temperature $\left({ }^{\circ} \mathrm{C}\right)$ is shown with the white contour lines in the lower plot. 